This item was submitted to Loughborough's Research Repository by the author.

Items in Figshare are protected by copyright, with all rights reserved, unless otherwise indicated.

\title{
Controlled failure warning and mitigation of prematurely failing beam through adhesive
}

PLEASE CITE THE PUBLISHED VERSION

http://dx.doi.org/10.1016/j.compstruct.2016.11.049

PUBLISHER

(C) Elsevier Ltd.

VERSION

AM (Accepted Manuscript)

\section{PUBLISHER STATEMENT}

This work is made available according to the conditions of the Creative Commons Attribution-NonCommercialNoDerivatives 4.0 International (CC BY-NC-ND 4.0) licence. Full details of this licence are available at: https://creativecommons.org/licenses/by-nc-nd/4.0/

\section{LICENCE}

CC BY-NC-ND 4.0

\section{REPOSITORY RECORD}

Khan, Mohammad Arsalan, Vadim Silberschmidt, and Jamal El-Rimawi. 2016. "Controlled Failure Warning and Mitigation of Prematurely Failing Beam Through Adhesive". Loughborough University. https://hdl.handle.net/2134/23614. 


\title{
Controlled failure warning and mitigation of prematurely failing beam through adhesive
}

\author{
Mohammad Arsalan Khan ${ }^{\mathrm{a}, *}$, Vadim V. Silberschmidt ${ }^{\mathrm{b}}$, Jamal El-Rimawi ${ }^{\text {a }}$ \\ ${ }^{a}$ School of Civil and Building Engineering, Loughborough University, Leicestershire, Loughborough LE11 3TU, United Kingdom \\ ${ }^{\mathrm{b}}$ School of Mechanical and Manufacturing Engineering, Loughborough University, Leicestershire, Loughborough LE11 3TU, United Kingdom
}

A B S T R A C T

\begin{abstract}
In plated beam, an adhesive is used primarily to adhere the external plate to the concrete beam to achieve a composite action. Even though some work has been found to indicate that the choice of softer adhesive increased the capacity of beam (MacDonald \& Calder, 1982), relatively stiffer adhesives have been largely assumed to provide better strengthening. Largely, due to the fact that adhesive has been widely consid-ered as an insignificant structural component towards the capacity of a composite beam; material capabilities (if not structural) of adhesive have also been ignored for further research towards studying its effects on premature failures (particularly debonding). Under mixedmode loading, the adoption through discretisation of Cohesive Zone Model as a bulk material (indicative of adhesive component) and to simulate interfacial cracks is shown here to achieve the objectives. The outcomes of the research indicate the critical material properties of adhesive in all directions, such as stiffness, strength and crack energy, play crucial role in controlling the behaviour of modes of failure. Further, based on this study, recommenda-tions have been proposed on the choice of adhesive type at different locations of plated beam so as to capture a failure warning and avoid catastrophic failure.
\end{abstract}

\section{Introduction: practical significance of failure modes}

An adhesively plated RC beam is susceptible to premature failures before it can attain its desired capacity, especially debonding and peeling due to their uncertain and brittle nature. Peeling is different than debonding in a way that former is caused as a consequence of formation and propagation of flexural crack at plate end, while latter is due to the formation of interfacial cracks at a composite interface (largely adhesive-concrete interface for plated RC beams). Focusing on debonding, the initial objectives of this paper is to associate possible modes of failure with debonding in terms of location of formation and/or propagation.

\subsection{Major debonding types}

\subsubsection{Mid-span debonding}

Sebastian [1] pointed out that debonding at mid-span debonding is a self-propagating process. In the flexural region of the beam,

\footnotetext{
* Corresponding author at: Department of Civil Engineering, Z. H. College of Engineering and Technology, Aligarh Muslim University, Aligarh 202002, Uttar Pradesh, India.

E-mail addresses: mohd.arsalan.khan@hotmail.co.uk (M.A. Khan), v.silberschmidt@lboro.ac.uk (V.V. Silberschmidt), j.a.el-rimawi@lboro.ac.uk (J. El-Rimawi).
}

intermediate cracks shall appear in the concrete substrate and the debonding would initiate at the toes of these cracks propagating outwards from high bending region to lower. It is observed that the crack will travel through the plane very close to concreteplate interface involving no concrete aggregate in the fracture plane.

The formation of flexural crack in concrete causes differential transverse deformations of the two materials at common interface; resulting into transverse stresses leading to failure due to interfacial crack (see Fig. 1). Alfano et al. [2] held accountable the propagation of such flexural cracks to cause localised yielding of reinforcement(s).

\subsubsection{Plate end interfacial debonding}

If the plate ends are discontinuous at supports, with increased mid-span deflection, plate will undergo slip at interface due to difference in material properties as well as deformation in normal direction due to relative stiffness.

To model the development of peak stresses at plate end, the FE model of Teng et al. [3] was in disagreement with the theoretical model of Smith and Teng [4]. The 3D FE model by Ascione and Feo [5], mainly adopted for predicting the shear and normal stresses in the adhesive layer of the plated RC beam, largely agreed with 


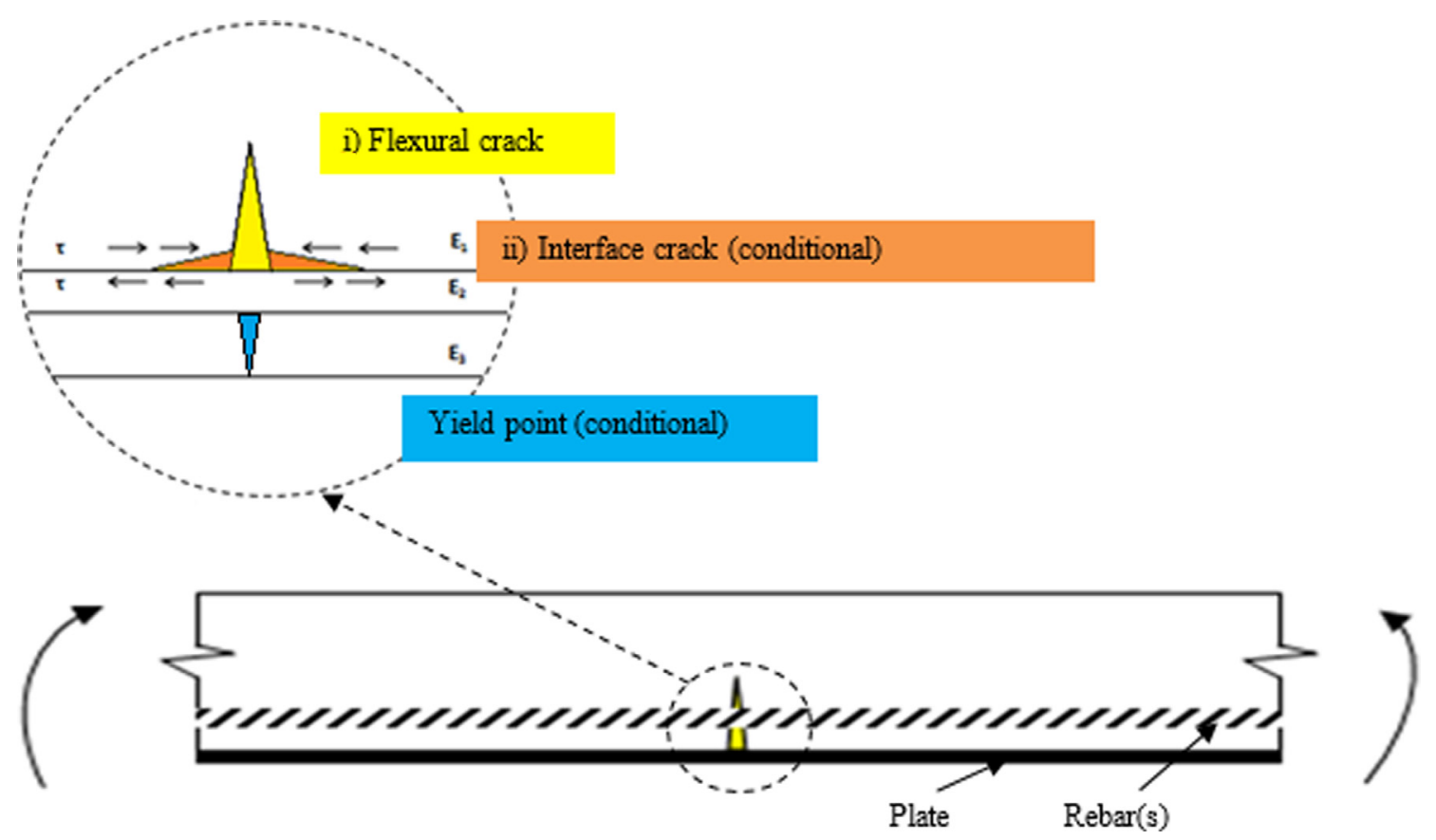

Fig. 1. Propagation of flexural crack along plate length.

the experimental test observations of Jones et al. [6]. When compared to real scenario, it is seen that, such behaviour of stress variation (particularly, at plate ends) does not emerge in analytical simplifications of Roberts [7], Roberts and Haji-Kazemi [8] and Oehlers [9]. Due to complexities in theoretical procedures, researchers such as De Lorenzis and Zavarise [10], could not quantify for non-linear material properties of the composite system for investigating plate end debonding.

\subsection{Parameters and their role on the behaviour of plated beam}

The use of epoxy adhesive, composed of a resin and a hardener, is a common practice in externally retrofitting concrete beams with FRP or steel $[11,12]$. Although, not as a significant structural strengthening component; however, as a component for structural integrity, the material properties of adhesive are likely to affect the premature capacity of the beam mainly in debonding. Therefore, in the present study, the theoretical and numerical framework at interface is devised to make viable the investigation on large number of adhesive parameters on modes of failure.

To tackle debonding due to adhesive, the selective material parameters include the elastic modulus of adhesive $E_{g}$, shear modulus of adhesive $G_{g}$, shear strength of interface $t_{s}^{\circ}$, normal strength of interface $t_{n}^{\circ}$, fracture energy of adhesive $G_{f g}$.

\subsubsection{Initial stiffness of adhesive}

In their FE model, Teng et al. [3] reported an increase in interfacial stresses with the increase in adhesive elastic modulus with modulus varying within the range of 2000-6000 MPa. Macdonald and Calder [13], altering adhesive stiffness in an unspecified range, found that it has virtually no significant effect on the loaddeflection behaviour of the beam; although, it was seen that the use of a stiffer adhesive generated more flexural cracks at a closer spacing than either the as-cast beams or plated beams using a flexible adhesive could show. The reason behind this behaviour was not identified or explained. Macdonald [14] qualitatively reported that soft adhesive has an advantage over stiff adhesive in that it is capable of withstanding movement while it is being cured.

\subsubsection{Shear strength of interface}

From literature, it is seen that the pull-off capacity for the plated beams using stiff adhesives is closer to the tensile strength of concrete. Reeve [15] found that the pull-off capacity for adhesives having elastic moduli of $4482 \mathrm{MPa}$ and $2227 \mathrm{MPa}$ were respectively $2.85 \mathrm{MPa}$ and $2.65 \mathrm{MPa}$, where the 28 day compressive strength of concrete was $23.3 \mathrm{MPa}$. Oh et al. [16] found that the shear strength of interface tested through double lap pull-out test varied with changing plate and adhesive thickness. For adhesive with modulus of elasticity of $2300 \mathrm{MPa}$, the average shear strength was observed within a range of $1.1 \mathrm{MPa}-2.5 \mathrm{MPa}$, where the 28 day compressive strength of concrete was $46.3 \mathrm{MPa}$, modulus of elasticity of $32,000 \mathrm{MPa}$, and the split tensile strength of $2.93 \mathrm{MPa}$. Jones et al. [6] achieved maximum interface bond strength of $5.01 \mathrm{MPa}$ (that is, for a mixed mode failure) for a concrete having an average compressive strength of $53.6 \mathrm{MPa}$ and the average splitting tensile strength of $3.55 \mathrm{MPa}$. Whereas, the observations made by Heathcote [17] have suggested an average value of $2 \mathrm{MPa}$ for the shear strength of interface.

\section{Method and numerical model}

\subsection{Method}

\subsubsection{Discretisation of material behaviour of a common interface}

One of the original theoretical concepts of fracture of concrete is extended in the context of current problem to illustrate the behaviour of common interface between two materials. Due to the formation of micro cracks in quasi-brittle materials or deformationsoftening materials, such as concrete, it is favourable to adopt crack energy equivalent to cracking strain for analysis.

Fig. 2 shows a typical stress-displacement relationship of a nonlinear material or composite interface generally subjected to tension or shear or both (mixed mode). Initially, as the force is increased, the equivalent behaviour at interface is demonstrated by average stiffness.

After certain loading, this is followed by a crack that initiates within a matrix of a weakest material. Unlike conventional 

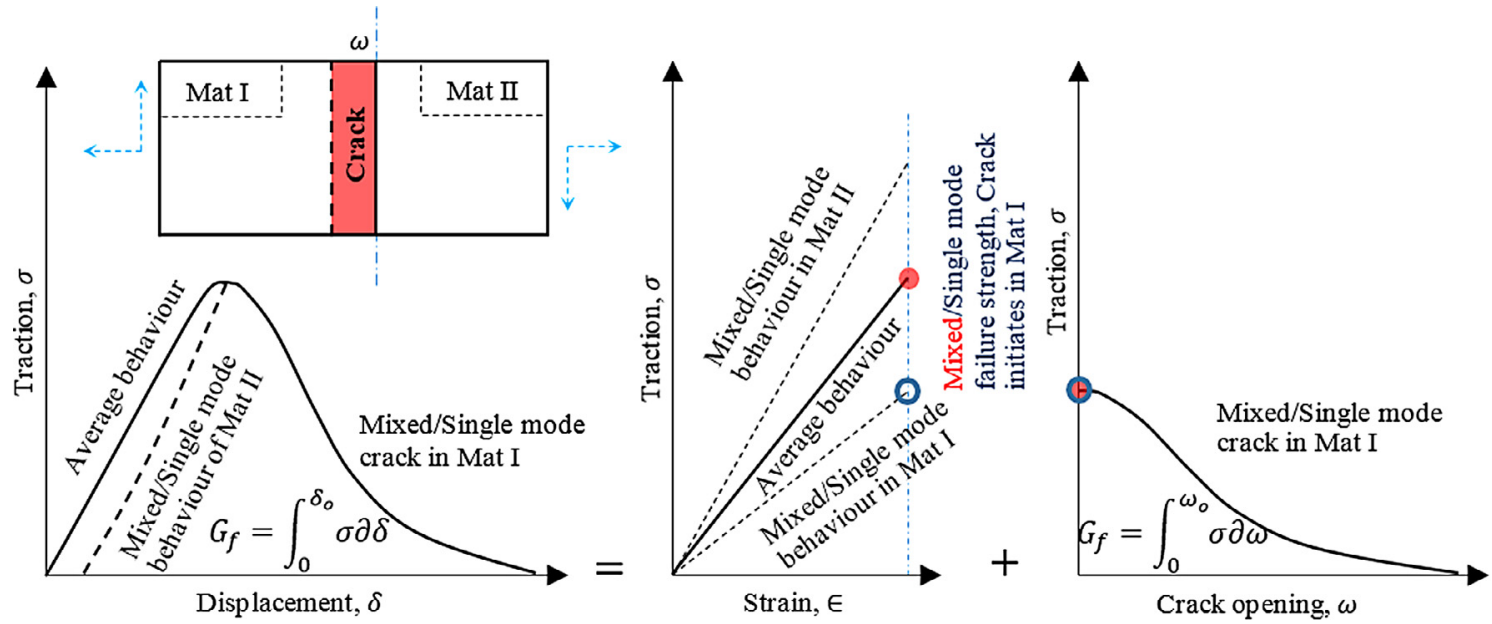

Fig. 2. Representative NLFM model for behaviour at common interface.

thinking, in present study, this weakest material is designed to be as adhesive (Mat I) rather than a concrete matrix (Mat II), so that the crack can now be adjusted to appear in adhesive layer without failing concrete. It is shown later on in this article that this can be achieved by adjusting the material properties of adhesive, or through the choice of adhesive type. If the mode of loading is unidirectional (single mode), the failure strength is denoted by blue circle; whereas, if the mode of loading is mixed-mode, it will have to satisfy a crack initiation criterion at red - dot as explained later on in Section 2.2.2. At this stage, the stronger (and uncracked) material would revert back to its original position of deformation.

After the failure strength/criteria at the interface is reached, the overall behaviour would follow the properties of failing material; that is now the crack energy of adhesive, and the associated deformation is termed as crack opening $\omega$.

\subsubsection{Relevance to $C Z M$}

As indicated by Rots [18,19], the initial stiffness of the element is assigned a large value (if not infinite) in order to hold to and bottom faces of the decohesion element; in this connection, an example of simulating an uncracked state with rigid connection between overlapping nodes can be associated with those analytically achieved by Meo and Thieulot [20]. Due to such modeling inaccuracies the latter author did not validate for the qualitative or quantitative accuracy of cracking. Their approach suffered from neglecting adhesive as a component during modeling; hence, the properties of numerical crack are representative of both the crack and material, and not exclusively the crack itself. Further, Allix et al. [21] adopted different values of high initial stiffness; however, the focus of their study was on post crack-initiation behaviour in single modes. Additionally, Li et al. [22] indicated that the cohesive law can be utilised to predict the transition between failure of composite and interface in mode-I. Recently, and in addition to the guidelines available in ABAQUS [23] towards considering geometrical and constitutive thickness in CZM, Corrado and Paggi [24] have extensively shown that the material and geometrical properties of adhesive (such as density or equivalent constitutive thickness) have a direct influence on the behaviour of CZM.

Therefore, to address the objectives of the study, current work associates the importance of initial stiffness and strength of cohesive law with the properties of adhesive so as to manufacture a desired crack in a desired material (here, adhesive); while the softening (that occurs after crack initiation) represents the property of cracking (failing) material. The differences between the old and present strategies are highlighted in Fig. 2.
In the context of present problem, this cracking surface is adjusted to emerge in adhesive. At the time of gluing an external plate on a casted concrete surface of an RC beam, it can be related from Figs. 2 and 3 that for a given properties of concrete matrix (Mat II), the initial stiffness of the adhesive (modeled using CZM as Mat I) can be assumed/picked such that the average initial stiffness of the interface can now be regulated as suggested in Fig. 3. In addition, the failure strength of the interface can be assigned by supplying strength of crack initiation (in Mat I, adhesive) relative to Mat II (concrete).

The weakest material is known and fails; after which the crack develops according to material property of failing material that can now be controlled to be within adhesive (and not necessarily within concrete as a conventional concept).

\subsection{Numerical model}

In the present FE model, both discrete and smeared crack models are combined to represent the full behaviour such that a Smeared crack model (Damaged Plasticity model) is used to capture strain localisation due to strain-softening and discrete crack model (CZM) is implemented to adopt to continuously changing integrity of the structure.

A 2D plane-stress approach is adopted for modeling using a FE software package ABAQUS. This analysis is a nonlinear static procedure with a classical Full-Newton solving method. A meshed model of a half-beam having $y$-axis symmetry at the middle of the beam, and other boundary conditions are briefed in Fig. 4 [25]. Maintaining the thickness of rebar layer equal to the diameter of rebar adopted, the sections within a beam are assigned the equivalent properties of steel rebars at the prescribed locations in compression and in tension. Element type for concrete and steel is a quadratic quadrilateral $2 \mathrm{D}$ continuum element with reduced integration (CPS8R), modeled with matching element sizes. A fine meshed cohesive layer, with unity base width, is staked along the length of RC beam between covercrete and external plate using a 4noded 2D cohesive element (COH2D4).

\subsubsection{Plasticity damaged model (continuum model)}

From the aspect that the irreversible damage may be required not only in fatigue loading but also as a consequence of stress redistribution due to geometric non-uniformities and cracking; the choice of Concrete Damaged Plasticity model for concrete and the Cohesive Zone Model (CZM) for adhesive are capable to retain damage to indicate closeness to real conditions. In addition, 


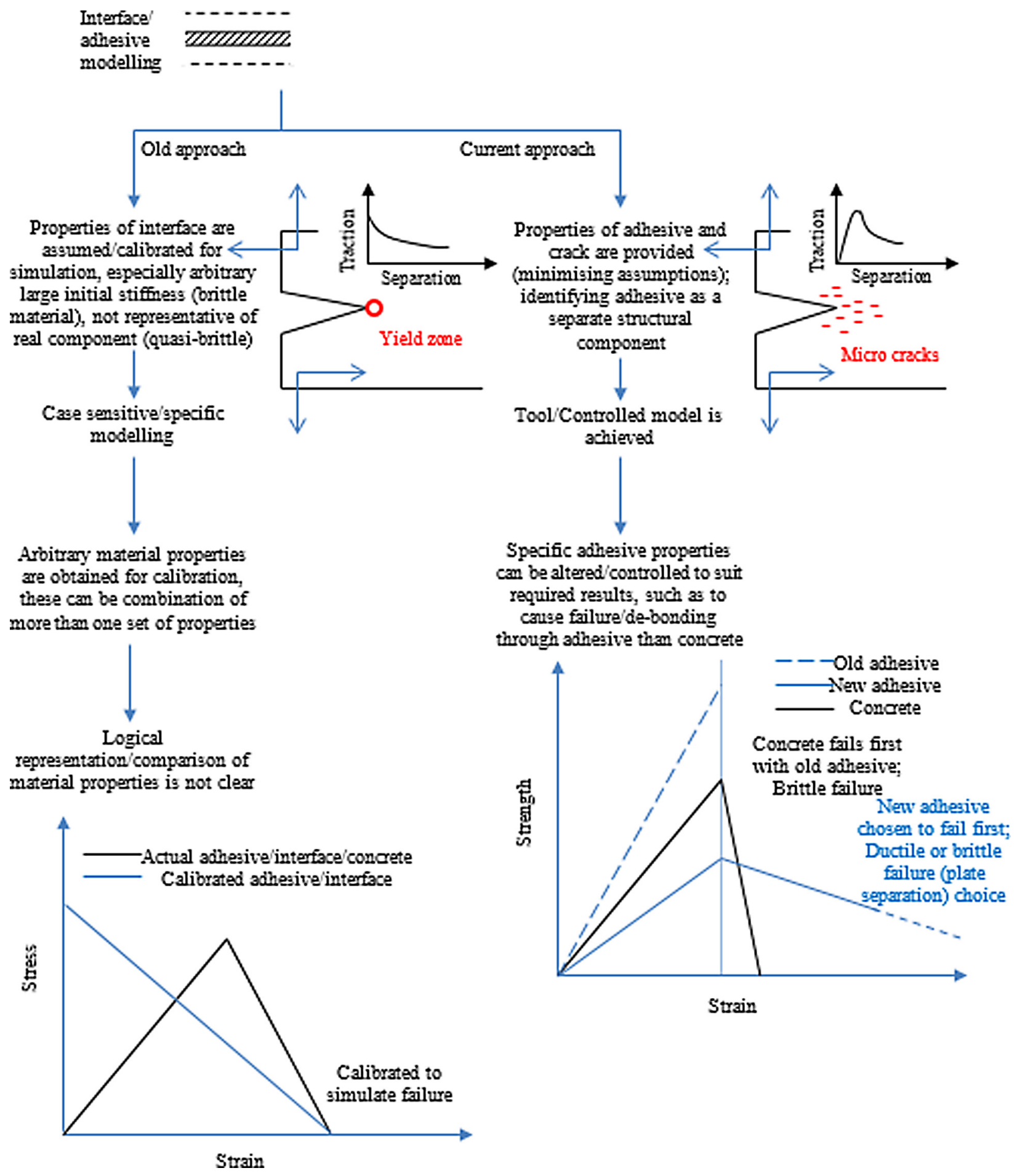

unlike Smeared Crack model, Concrete Damaged Plasticity model assumes the retention of permanent plastic strain (not total strain values) after damage initiation (both in tension and compression concrete).

\subsubsection{Implementation of CZM (discrete model)}

CZM can be implemented at a predefined location to demonstrate the formation of crack or slip between the two surfaces at a common interface. In addition, it is also acknowledged in this study that CZM can also be used to define a bulk material such as adhesive.

As outlined by Khan [25], pertaining to the uncertainty of occurrence of debonding to a specific location in plated beam, cohesive layer is embedded along the length of the plate. This layer is modeled at the same location as adhesive so as to utilise CZM both for defining adhesive (before crack initiation) as well as debonding (as crack initiates). In CZM, the characteristics of a bulk material can be maintained through assuming the value of initial stiffness (penalty stiffness) equivalent to elastic modulus of a bulk material. This can be done through maintaining the constitutive thickness of cohesive layer as unity adopted for equivalent geometrical thicknesses. 


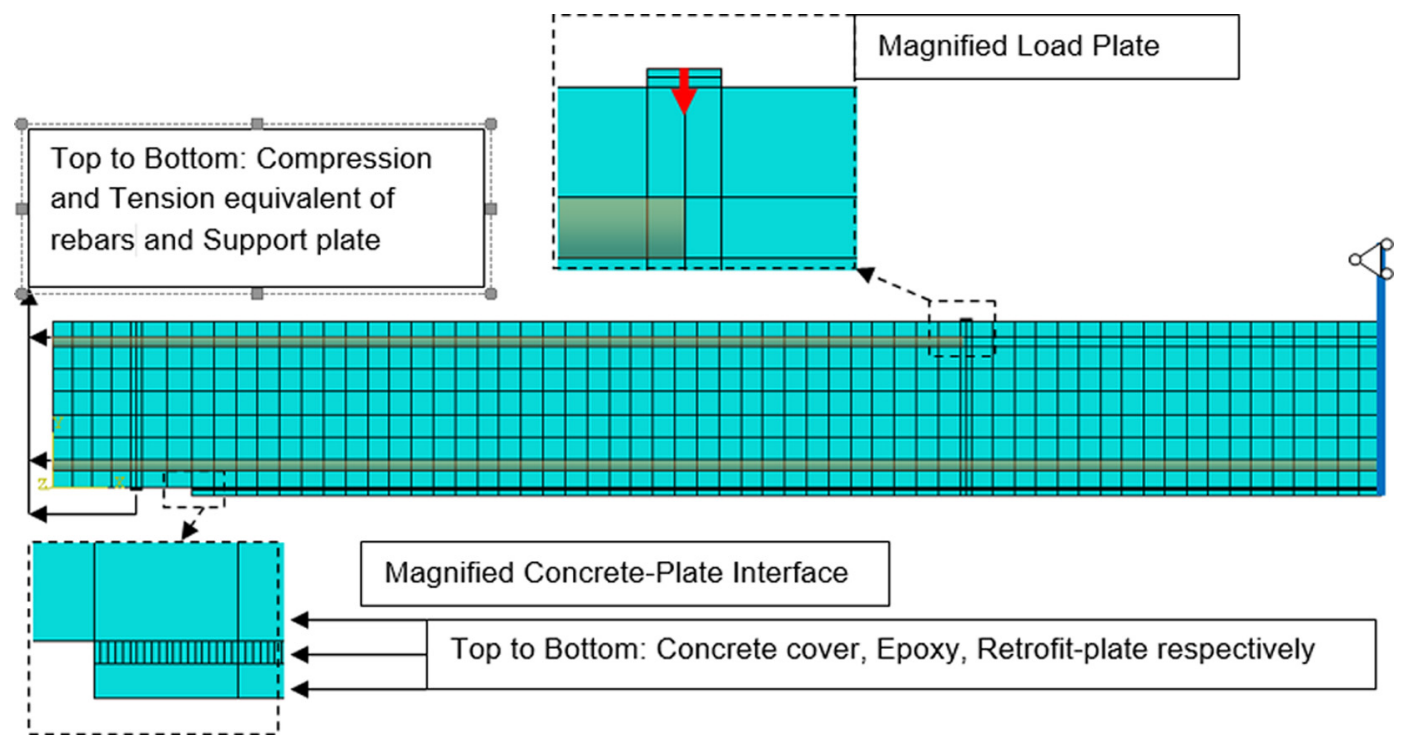

Fig. 4. M20 mesh layout for plated beam and boundary conditions.

The material properties of adhesive can be determined through: Double Cantilever Beam (DCB) test for Mode I, End-Notched Flexure (ENF) or End-Loaded Split (ELS) test for Mode II. The material properties of concrete can be deducted through 3-point loaded notched beam in Mode I, and push tests for Mode II. Mixed modes I and II behaviour can be deduced through Mixed Mode Bending (MMB) test [19].

Mixed-mode behaviour: For interfacial delamination between two dissimilar materials or a non-isotropic material, the mode mix is commonly observed. In ABAQUS, the traction-separation laws for the opening (mode I in normal direction) and shearing (mode II in transverse direction) can be defined independent to each other, each with a set of similar parameters. The behaviour of the formation of crack can then be defined with the rules of crack initiation, propagation and complete failure.

A detailed representation of a two-dimensional form of the bilinear traction separation behaviour in mixed mode loading condition is summed up in Fig. 5. It shows that the parameters required to define the interfacial (cohesive) elements with the properties of adhesive can be the initial elastic stiffness or elastic modulus $K_{g}$ and cohesive strength $\left(t_{n}, t_{s}\right)$; and to tackle debonding, a maximum separation $\delta_{m}^{f}$ or overall fracture energy or toughness $G_{f}$ can be utilised. For numerical implementation, the value $G_{f}$ for mixed mode I and II can be obtained: using MMB test by setting different mixedmode ratios to match the experimental observations, or by combining overall fracture energies in mode I and II obtained through single mode of loadings and corresponding to $G_{f \sigma}$ and $G_{f \tau}$. For numerical implementation, the value $G_{f}$ for mixed mode I and II can be obtained: using MMB test by setting different mixed-mode ratios to match the experimental observations [19], or by combining overall fracture energies in mode I and II obtained through single mode of loadings and corresponding to $G_{f \sigma}$ and $G_{f \tau}$.

A damage parameter $D_{m}$ is used to describe the state of the interface, which evolves from 0 (no damage) to 1 (failure) based on a damage evolution rule:

$D_{m}= \begin{cases}0 & , \delta_{m} \leqslant \delta_{m}^{\circ} \\ \frac{\delta_{m}^{f}\left(\delta_{m}^{\max }-\delta_{m}^{\circ}\right)}{\delta_{m}^{\max }\left(\delta_{m}^{f}-\delta_{m}^{\circ}\right)} & , \delta_{m}^{\circ}<\delta_{m}^{\max }<\delta_{m}^{f} \\ 1 & , \delta_{m} \geqslant \delta_{m}^{f}\end{cases}$

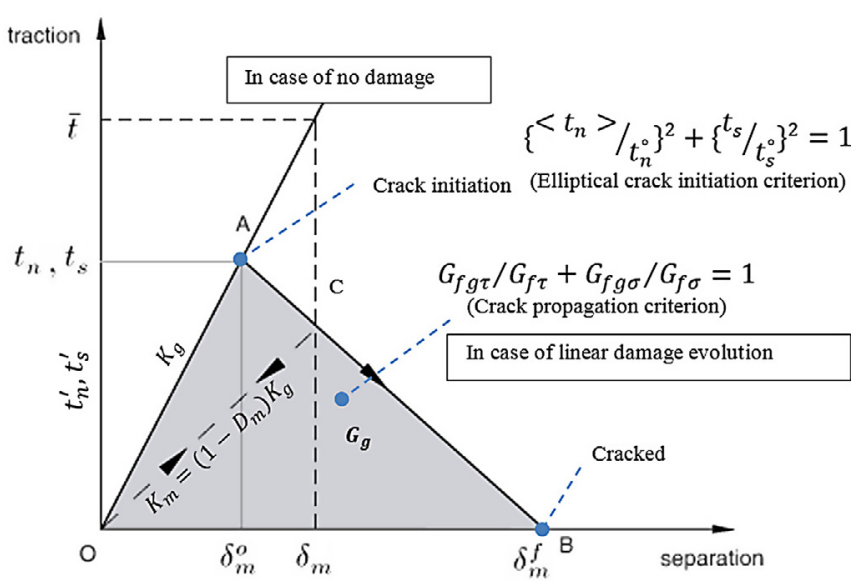

Fig. 5. Traction-displacement model for mixed mode behaviour (modified after ABAQUS).

$\delta_{m}$ represents mixed mode displacement, $\delta_{m}^{\circ}$ represents mixed mode displacement at crack initiation, $\delta_{m}^{\max }$ represents a maximum mixed mode displacement reached after crack initiation, $\delta_{m}^{f}$ represents mixed mode displacement at complete failure. For $\delta_{m} \geqslant \delta_{m}^{f}$, $D_{m}=1$ and $t_{m}=0$; this indicates that the interface element is completely eroded to transfer any further stresses across its boundaries. In ABAQUS [23], an output command SDEG indicates damage $D$. During unloading (for example, from $\mathrm{C}$ to $\mathrm{O}$ ), $\delta_{m}^{\max }$ (highest value of mixed mode displacement $\delta_{m}$ reached) remains constant and so does $D_{m}$. Therefore, the stress decreases linearly as the opening displacement decreases, with the slope $K_{m}$ as illustrated by the dashed line.

For given material or interface, the values of $\delta_{m}^{f}$ are directly dependent on the fracture energy dissipated or work done $G_{f g}$ by tractions to demonstrate the overall behaviour (including cracking). Therefore, $G_{f g}$ has been categorised as:

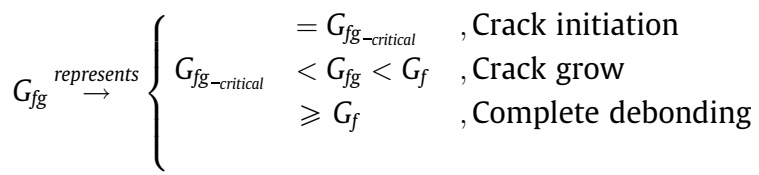


Where, $G_{f g \_c r i t i c a l}$ is the mixed-mode fracture energy at the interface at crack initiation. With increased loading, crack grows until complete debonding that occurs at $G_{f} . G_{f}$ represents the total fracture energy (fracture toughness) available from start of loading through to complete failure. Therefore, to suite present methodology, the fracture energy dissipated $G_{f g}$ at a given instant is broken down as:

$G_{f g}=G_{f g \_ \text {critical }}+G_{f c \_ \text {interface }}$

$G_{f g}$ represents fracture energy dissipated in mixed mode loading at a given instant. $G_{f \_ \text {_interface }}$ is the crack energy dissipated in mixedmode fracture after crack initiation, this category represents the property of a failing surface from crack initiation to complete failure (debonding) at $G_{f_{-} \text {interface }}$.

That is, at complete failure:

$G_{f}=G_{f g \_c r i t i c a l}+G_{f \_ \text {interface }}$

(a) Crack Initiation Criterion: For simplicity, an elliptical damage initiation criterion is chosen:

$\left\{\left\langle t_{n}\right\rangle / t_{n}^{\circ}\right\}^{2}+\left\{t_{s} / t_{s}^{\circ}\right\}^{2}=1$,

Where $t_{s}^{\circ}$ is the shear strength of the interface, $\left\langle t_{n}\right\rangle=t_{n}$ if $t_{n}>0$ (tension) and $t_{n}=0$ otherwise. The Macauley bracket assumes that compression does not cause damage.

The mixed mode stress $\left(t_{m}^{\circ}\right)$ can be evaluated as:

$t_{m}^{\circ}=\sqrt{\left(t_{n}\right)^{2}+\left(t_{s}\right)^{2}}$.

The mixed-mode displacement can be determined through:

$\delta_{m}^{\circ}=\sqrt{ }\left(\left\langle\delta_{n}^{\circ 2}\right\rangle+\delta_{s}^{\circ 2}\right)$

The individual displacements are evaluated at their respective stress components $\left(t_{n}\right.$ and $\left.t_{s}\right)$, at which the crack initiation criterion is fulfilled:

$\delta_{n}^{\circ}=t_{n} / K_{g \sigma}$.

$\delta_{s}^{\circ}=t_{s} / K_{g \tau}$.

Where $K_{g \sigma}$ and $K_{g \tau}$ represent the initial elastic stiffness (of bilinear adhesive material) until crack initiation in mode-I and mode-II directions respectively.

Depending on the analysis, at the initiation of mixed-mode failure (at $\delta_{m}^{\circ}$ ), the value of traction in normal direction $t_{n}$ may or may not be equal to the value of the traction in transverse direction $t_{s}$.

Once the value of $\delta_{m}^{\circ}$ is known, the critical crack energies in the normal $G_{f g \sigma_{-} \text {critical }}$ and transverse $G_{f g \tau_{\text {_critical }}}$ directions at the time of crack initiation can be evaluated:

$G_{f g \sigma_{-} \text {critical }}=0.5 t_{n} \delta_{m}^{\circ} b_{\text {FEM }}$

$G_{f g \tau_{-} \text {critical }}=0.5 t_{s} \delta_{m}^{\circ} b_{\text {FEM }}$

Where $b_{F E M}$ is a characteristic elemental length adopted in the finite-element model (it is unity for a cohesive element).

(b) Crack Propagation Criterion: Similar to single mode, at a given damage variable, the values of $t_{n}^{\prime}$ and $t_{s}^{\prime}$ can be written:

$t_{n}^{\prime}=\left\{\begin{aligned}\left(1-D_{m}\right) \bar{t}_{n}=\left(1-D_{m}\right) K_{g \sigma} \delta_{n} & , \delta_{n} \geqslant \delta_{n}^{\circ}, \\ \bar{t}_{n} & ,(\text { no damage })\end{aligned}\right.$

$t_{s}^{\prime}=\left(1-D_{m}\right) \bar{t}_{s}=\left(1-D_{m}\right) K_{g \tau} \delta_{s}$,
Where $\bar{t}_{n}$ and $\bar{t}_{s}$ are the stress components predicted by the elastic traction-separation behaviour (that is, without damage) at the corresponding separations (see Fig. 5).

The maximum mixed mode displacement $\delta_{m}^{\max }$ is related to the normal $\delta_{n}$ and tangential $\delta_{s}$ components as:

$\delta_{m}^{\max }=\sqrt{ }\left(\left\langle\delta_{n}^{2}\right\rangle+\delta_{s}^{2}\right)$.

At this stage, the normal $\delta_{n}$ and tangential $\delta_{s}$ components of equivalent displacement are related to their corresponding stress components as:

$\delta_{n}=\bar{t}_{n} / K_{g \sigma}$

$\delta_{s}=\bar{t}_{s} / K_{g \tau}$

At this stage, the crack energies dissipated in normal and transverse directions are given as:

$G_{f c \sigma \_ \text {interface }}=0.5 t_{n}\left(\delta_{m}^{\max }-\delta_{m}^{\circ}\right) b_{\mathrm{FEM}}$,

$G_{f c \tau \_ \text {interface }}=0.5 t_{s}\left(\delta_{m}^{\max }-\delta_{m}^{\circ}\right) b_{F E M}$.

(c) Complete Failure Criterion: The failure criterion for complete debonding is adopted as energy based:

$G_{f g \tau} / G_{f \tau}+G_{f g \sigma} / G_{f \sigma}=1$

Where $G_{f \tau}$ and $G_{f \sigma}$ are equivalent to fracture toughness under pure mode-II (shearing) and mode-I (opening) conditions, respectively, $G_{f g \tau}$ and $G_{f g \sigma}$ are the work done by the tractions in transverse and normal directions:

$G_{f g \tau}=\int_{0}^{\delta_{s}} t_{s}^{\prime} \partial \delta_{s}$

$G_{f g \sigma}=\int_{0}^{\delta_{n}} t_{n}^{\prime} \partial \delta_{n}$

$G_{f \sigma}=G_{f g \sigma_{-} \text {critical }}+G_{f \sigma \_ \text {interface }}$

$G_{f \tau}=G_{f g \tau_{-} \text {critical }}+G_{f \tau_{\_} \text {interface }}$

The condition (Eq. (19)) is satisfied at $D_{m}=1$, with $\delta_{m}^{\max } \rightarrow \delta_{m}^{f}$, that is the maximum value of displacement $\delta_{m}^{\max }$ approaches the failure displacement $\delta_{m}^{f}$. The value of $\delta_{m}^{f}$ can be calculated if the fracture energy of crack $G_{f_{-} \text {interface }} t_{s} t_{n}$ is known:

$\delta_{m}^{f}=G_{f \_ \text {interface }} /\left(0.5 t_{m}^{\circ} b_{\text {FEM }}\right)+\delta_{m}^{\circ}$.

Once the value of $\delta_{m}^{f}$ is known, the total crack energies in the normal $G_{f \sigma} \sigma_{-}$interface and transverse $G_{f \tau_{\_} \text {interface }}$ directions can be given:

$G_{f \sigma \_ \text {interface }}=0.5 t_{n}\left(\delta_{m}^{f}-\delta_{m}^{\circ}\right) b_{F E M}$,

$G_{f \tau \text { _interface }}=0.5 t_{s}\left(\delta_{m}^{f}-\delta_{m}^{\circ}\right) b_{F E M}$.

Therefore, at $\delta_{m}^{\max }$ (where, $\delta_{m}^{\circ} \leqslant \delta_{m}^{\max } \leqslant \delta_{m}^{f}$ ), damage variable $D_{m}$ can be calculated (see Eq. (1)).

It is noted that Eqs. (25) and (26) involve the role of parameters $G_{f \_ \text {interface }}, \delta_{m}^{\circ}, t_{n}$ and $t_{s}$, while the values of $t_{n}$ and depend on $G_{f g \_c r i t i c a l}$ when the failure initiation criterion is fulfilled. Depending upon the release of energy $G_{f g_{-} \text {critical }}$ at crack initiation at $\delta_{m}^{\circ}$, or $t_{s}$ may or may not change. It suggests that the value of $\delta_{m}^{f}$ is directly dependent on the value of $G_{f_{-} \text {interface }}$. 


\section{Materials and parameters at interface}

\subsection{Shear and tensile stiffness of adhesive at interface}

Charif [26] tested specimens for determining the range of properties for a two part epoxy adhesive. The initial test modulus of elasticity (determined by the tangent at the origin of the stressstrain curve) ranged from 428.1 MPa to 2081.7 MPa, secant modulus (determined as an average value over a longitudinal strain of 0.02 ) varied from $230.4 \mathrm{MPa}$ to $663.0 \mathrm{MPa}$, the initial Poisson's ratio varied from 0.55 to 0.72 , and 0.48 to 0.64 for average at 0.02 of longitudinal strain. A $1.5 \mathrm{~mm}$ epoxy adhesive by Jones et al. [6] had an initial modulus of $801 \mathrm{MPa}$ and average at 0.02 elongation of $278.9 \mathrm{MPa}$, the initial and average at 0.02 elongation poisons ratio was 0.70 and 0.58 respectively. Clearly, these values of Poisson's ratio are theoretically incorrect, thereby indicating the inaccuracies in experimental results. The corresponding shear modulus of elasticity is now calculated as $235.59 \mathrm{MPa}$ for initial modulus of $801 \mathrm{MPa}$.

Covering a wide range of epoxy adhesives detailed by Charif [26] and Sikadur [27], the values for the initial stiffness $K_{g \tau}$ of the interface in transverse direction are evaluated to be around $250 \mathrm{MPa} / \mathrm{mm}$ (soft), $500 \mathrm{MPa} / \mathrm{mm}$ (medium) and $2000 \mathrm{MPa} / \mathrm{mm}$ (very stiff) respectively at $25 \%, 50 \%$ and $200 \%$ of the reference value of 991.4 MPa/mm (stiff); the assumptions are plotted in Fig. 6.

While keeping failure strength of interface unchanged, the value of overall fracture energy $G_{f}$ will also change due to the change in the initiation fracture energy $G_{f \text { interface }}$ to cover a large practical range.

In general, the change in the stiffness of adhesive in one direction would accordingly influence the overall stiffness (resultant component) of the adhesive for a mixed mode problem (refer Fig. 2). In addition, to fill the gap in literature, the stiffness of the adhesive is varied in normal direction to cover a broad range of $575-4600 \mathrm{MPa} / \mathrm{mm}$ (reference value is $2300 \mathrm{MPa} / \mathrm{mm}$ ).

\subsection{Shear and tensile strengths at interface}

As desired, it can now be assumed that the failure strength in the transverse direction $t_{s}^{\circ}$ is achieved through the properties of adhesive (or interface) so that a crack can initiate in adhesive rather than in concrete. A practical range is incorporated by assuming traction-separation behaviour shown in Fig. 7, at 50\% and 200\% of shear strength of $2 \mathrm{MPa}$ (reference value) that yields the shear strengths of $1 \mathrm{MPa}$ and $4 \mathrm{MPa}$ respectively. At this stage, to evaluate the effect(s) of shear and tensile strengths, other parameters are fixed, such as the total interface fracture energy $G_{f}$ or toughness is maintained at $0.044 \mathrm{~N} / \mathrm{mm}$.

In case of tensile strength, design code BS8110 [28] considers the value of concrete tensile strength $f_{t c}$ to be $10 \%$ of concrete cubic compressive strength $f_{c u}$ and ACI code [29] as 0.33 times of the square root of concrete compressive strength $f_{c}^{\prime}$. In order to allow for the crack to initiate within adhesive, new values of normal strength are taken to be lower than the tensile strength of adjacent concrete (at $2.87 \mathrm{MPa}$ ) such as those of Polyvinyl acetate latex (PVA) [30]. In plated beams of this study, it is generally noted that the rate of development of stresses in the normal direction is less than the rate in transverse direction [25]. Based on this observation, the values of normal strength $t_{n}^{\circ}$ are taken as fractions that of shear strength $t_{s}^{\circ}$ (of $2 \mathrm{MPa}$ ). The reference value for normal strength lies at $t_{n}^{\circ}\left(=143.5 \% t_{s}^{\circ}\right)$. At $50 \% t_{s}^{\circ}$ and $25 \% t_{s}^{\circ}$, the assumed values of normal strength $t_{n}^{\circ}$ are $1 \mathrm{MPa}$ and $0.5 \mathrm{MPa}$ respectively.

\subsection{Crack energy at interface}

After a crack initiates, the load required to form a complete crack is dependent on the available crack energy. By definition,

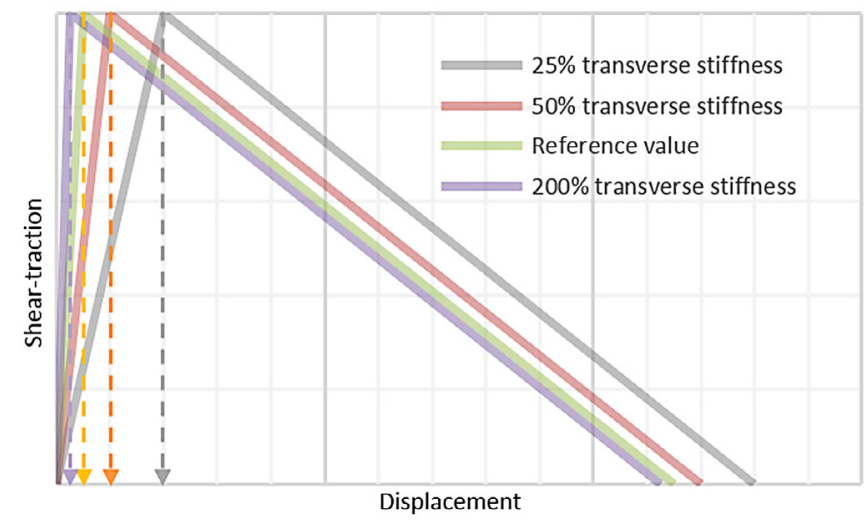

Fig. 6. Initial stiffness of adhesive $K_{g \tau}$ as a variant.

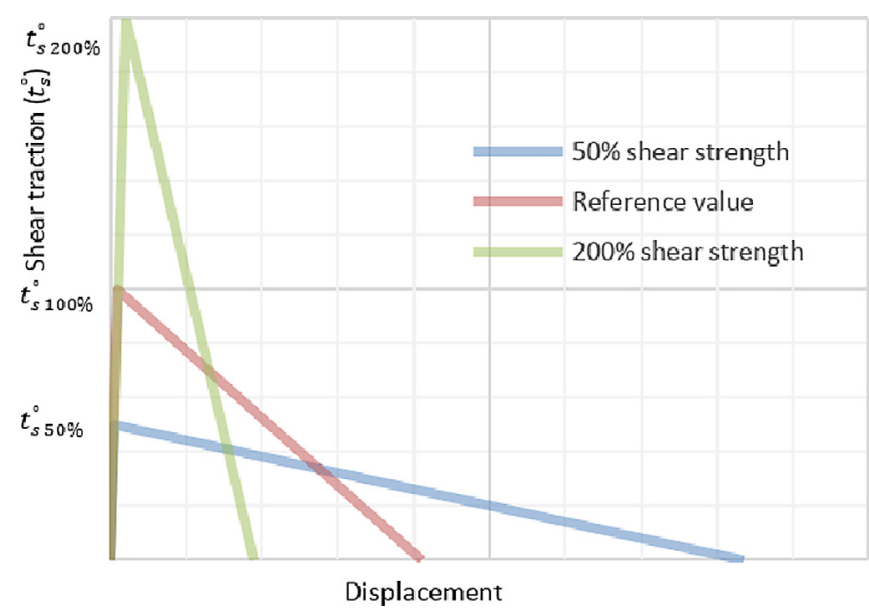

Fig. 7. Assumed models for interface shear strength $t_{s}^{\circ}$.

the crack energy $G_{f \_ \text {interface }}$ is the amount of potential work restored per unit crack area. Therefore, it corresponds to the material property of a cracking surface. And this is different from overall fracture energy or material toughness $G_{f}$. Any changes in $G_{f \text { _interface }}$ would be reflected through changes in tension softening after crack initiation; this would directly affect the material toughness or overall fracture energy $G_{f}$. Changes in adhesive type may directly affect crack energy, depending on the elongation of adhesives after crack initiation.

In terms of material and geometrical variables, the expression for $G_{f \_ \text {interface }}$ can be given by:

$G_{f_{\text {_interface }}}=0.5\left(n e_{t}\right) f b_{\text {FEM }}$

Depending on the nature of cracking/failing material (at interface), $e_{t}, f$ and $b_{F E M}$ represent plastic tension strain, tensile strength

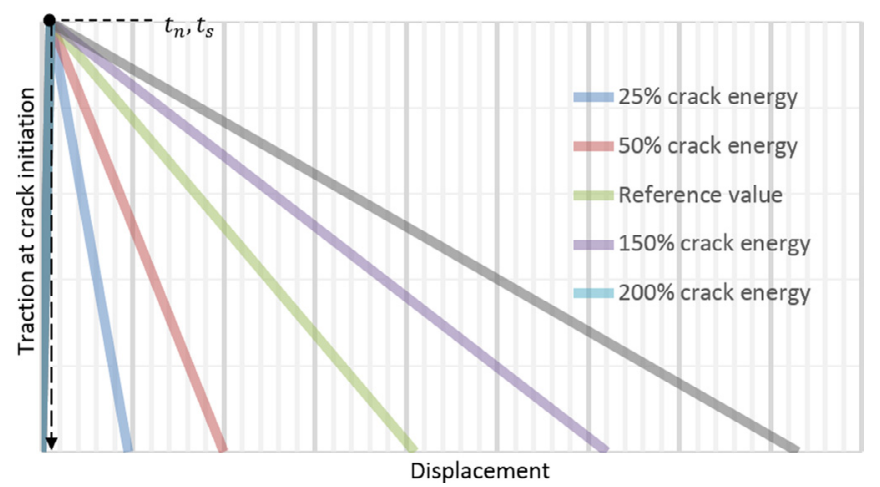

Fig. 8. Overall energy of interface $G_{f}$ as a variable at debonding failure. 


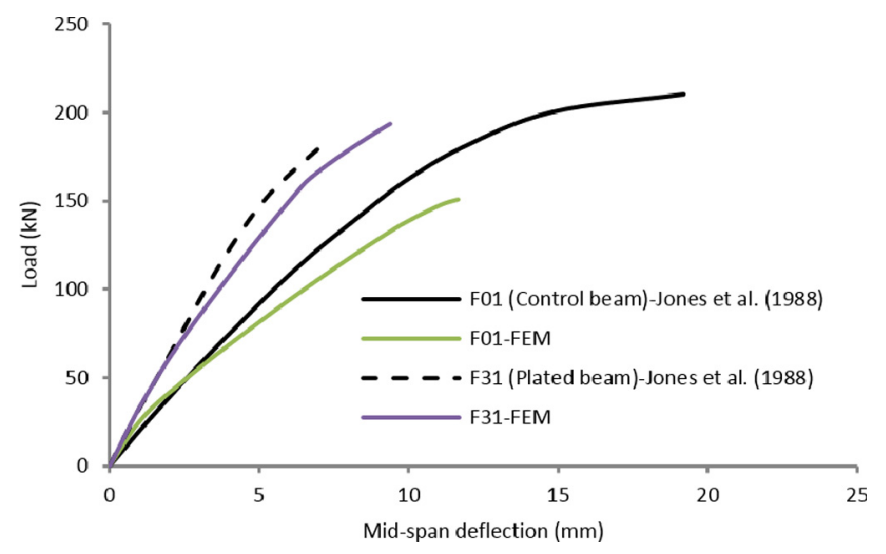

Fig. 9. Load verses Mid-span deflection.

of concrete or adhesive and characteristic elemental length adopted in finite element model respectively. $n$ is a numeric strain multiplier controlling strain softening in tension.

In most cases, concrete can be highly brittle while adhesive can be highly ductile. In practice, the interface fracture energy might also depend on the surface preparation. In case of hardened cement paste (with maximum aggregate size of $0.01 \mathrm{~mm}$ ), Wittmann [31] summarised the range for $G_{f \_ \text {interface }}$ as $0.0095-0.05 \mathrm{~N} / \mathrm{mm}$. The elongation at break for different structural adhesive at different time periods generally varies within the range of $0.2-1.2 \%$ [27]. The fracture energy for crack in the cured epoxy and filled resins ranged from approximately $10^{-3}-0.5 \mathrm{~N} / \mathrm{mm}$ [32], which includes the energy absorbed before maximum strength is reached. Therefore, in order to cover a wide range of crack energies, the value of $G_{f \text { interface }}$ is varied at $25 \%(=0.0105 \mathrm{~N} / \mathrm{mm}), 50 \%(=0.021 \mathrm{~N} / \mathrm{mm}), 150 \%(=0.063 \mathrm{~N} / \mathrm{mm})$ and $200 \%(=0.084 \mathrm{~N} / \mathrm{mm})$ of reference value $(0.042 \mathrm{~N} / \mathrm{mm})$. To indicate the relative elongation in strain, the corresponding values of $n$ are evaluated to be $7.5,15,45$ and 60 respectively compared to the reference value of 30 .

The assumptions are represented in the form of tractionseparation diagram in Fig. 8.

\section{Results}

\subsection{Validation}

Khan [25] has shown broad validations for general behaviour of prematurely failing beams; whereas, this paper primarily reports on the behaviour of interfacial cracks.

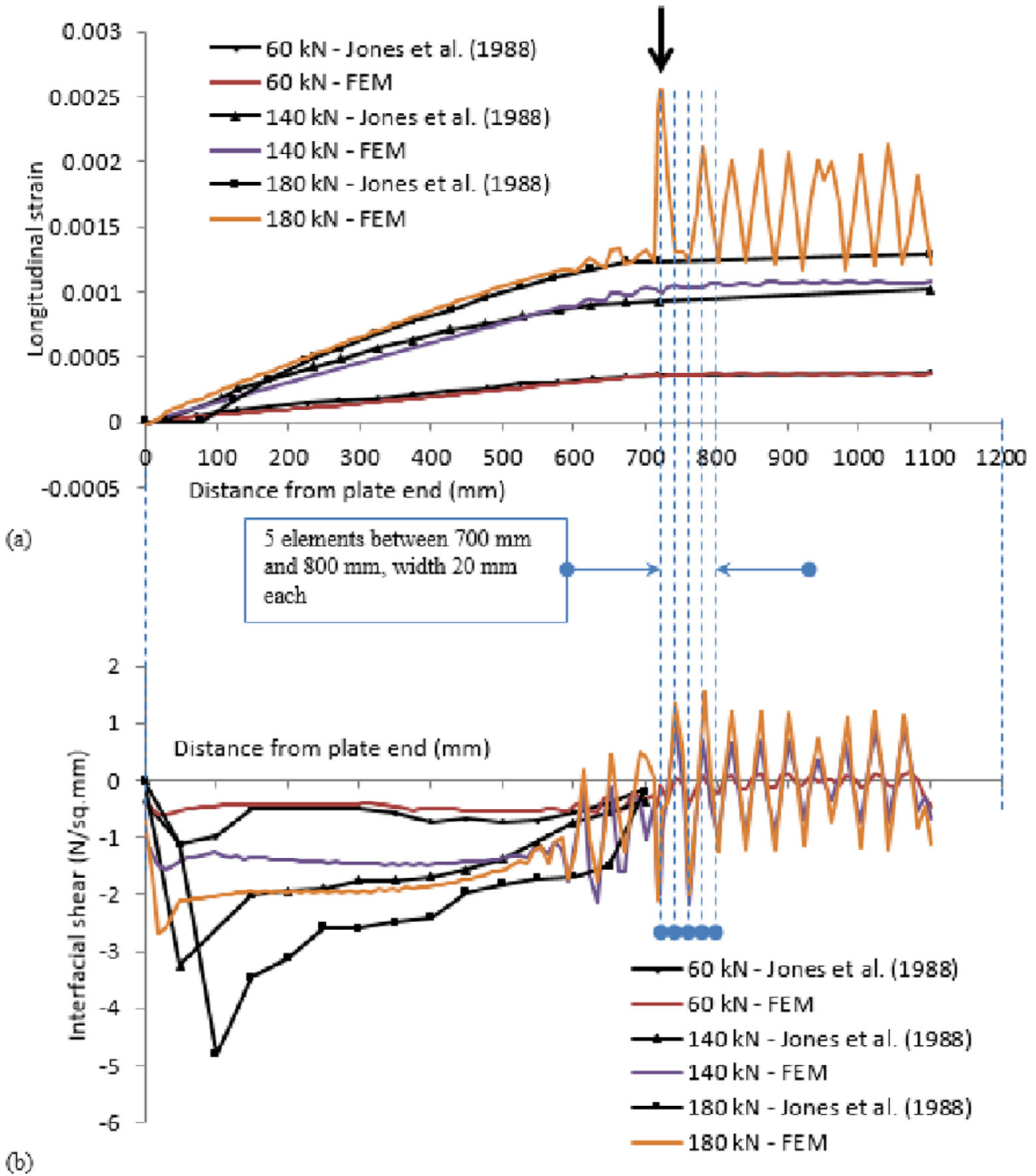

Fig. 10. (a) Longitudinal strain distribution along the plate, (b) stress distribution in transverse direction along the plate length. 


\subsubsection{Specimens of Jones (Jones et al. [6])}

The validation studies for load-deflection behaviour (see Fig. 9), distribution of longitudinal strains along the plate length for a given load (see Fig. 10a), the shear stress distribution along the adhesive-covercrete interface (see Fig. 10b) and the effect of the choice of initial shear stiffness of adhesive on distribution of shear stress at adhesive-covercrete interface are shown next (see Fig. 11a).

Fig. 10 shows that the initial stiffness for the FE beams are in close agreement with the experimental beams. With increased loading, the stiffness of numerical beams reduces slightly; however, the modes of failure remain same. The final capacities of the FE beams, F01 and F31, are noted to be $151 \mathrm{kN}$ and $193.7 \mathrm{kN}$ as compared to experimental results of $210 \mathrm{kN}$ and $180 \mathrm{kN}$ respectively. Specimens F01 and F31 show that the second beam has a larger capacity, while the FE simulations have an opposite behaviour; it is because the unplated beam F01 could take additional load during real testing as the reported mode of failure was flexural crushing of concrete after yielding of the rebars. Whereas, the current numerical model is not designed to fail in concrete-crushing due to its predictable nature of failure [25]; concrete crushes when the beam reaches desired capacity in compression.

In Fig. 10b, the development of stress concentrations are observed at plate end as the load is increased. As expected, the average transverse stress is zero at mid-span; however, the local stresses (the fluctuations) are developed at mid-span mainly as a result of discontinuities due to the formation of flexural cracks. Due to practical limitation in extracting data through laboratory tests of Jones et al. [6], such behaviour is now expressed more in detail using FE model. The irregularities in plots are captured due to the choice of plasticity damage model and the spacing of such irregularities is dependent on mesh size. They are helpful in predicting stress/strain variations due to cracks; for example, in Fig. 10a the peaks indicate the location of flexural crack, while in Fig. 10b the effect of such flexural cracks can be seen to develop interfacial stresses propagating in both directions. At any location, such stresses are seen to increase with increase in flexural strains.

Interface stress of 5.01 MPa was manipulated for $6 \mathrm{~mm}$ plated section [6]. According to theoretical evaluation by Ascione and Feo [5], the peak stress at plate-end at the loads of $60 \mathrm{kN}, 140 \mathrm{kN}$

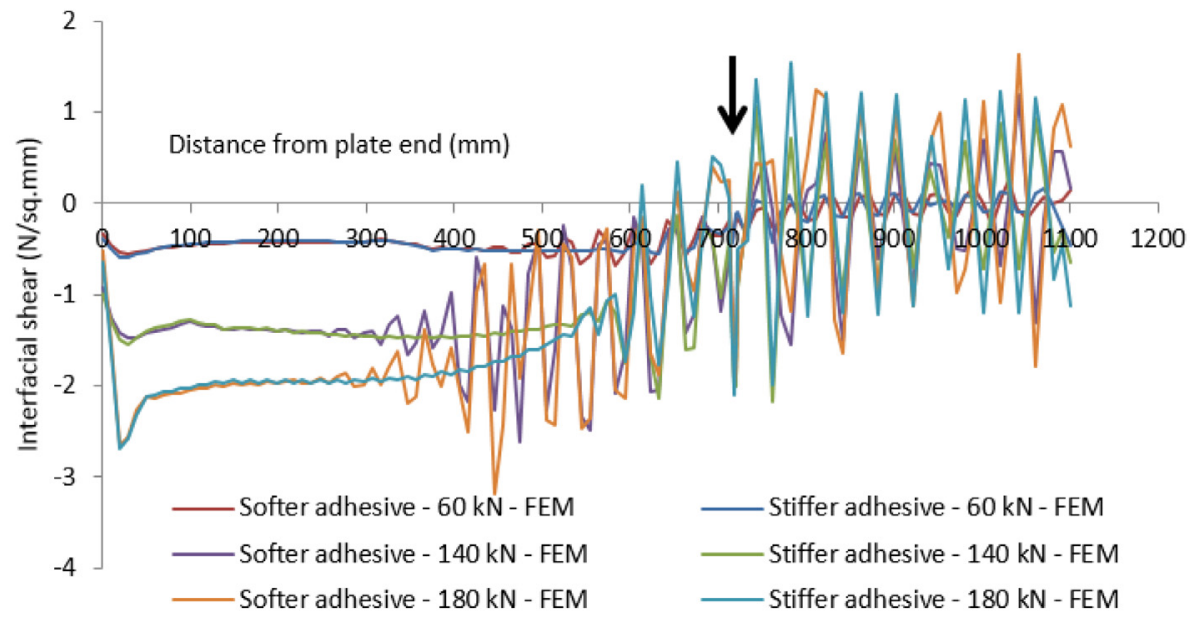

(a) Distribution of transverse stresses

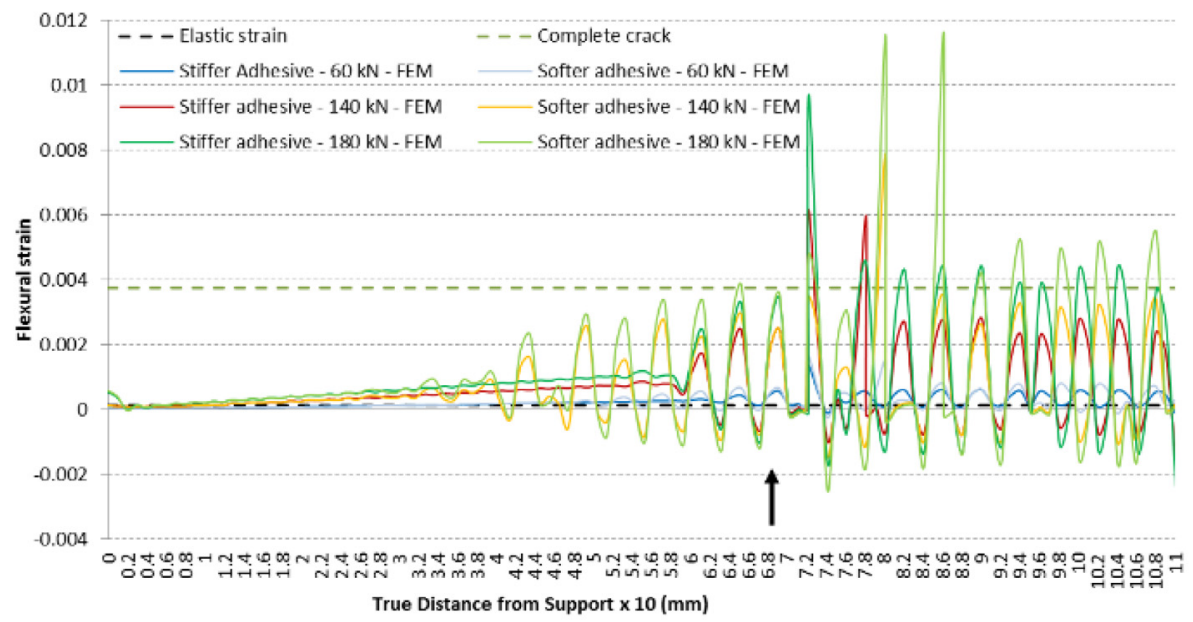

(b) Distribution of flexural strains

Fig. 11. Effect of choice of adhesive's initial stiffness on transverse stresses and flexural strains at concrete-adhesive interface. 


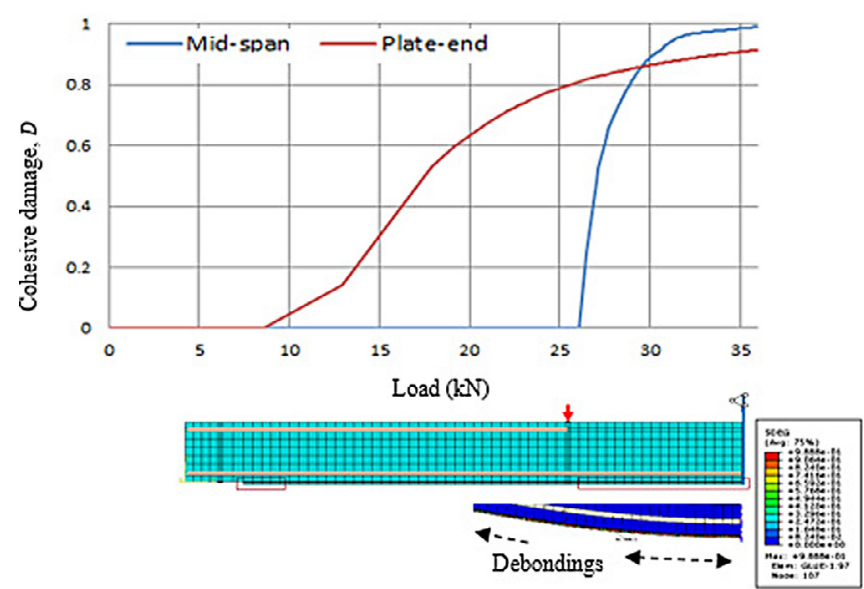

Fig. 12. Debonding modes (beam URB2): interface damage at critical locations.

and180 kN were 0.9 MPa, 2.1 MPa and 2.7 MPa respectively, which is close to as established in the present FE model of $0.6 \mathrm{MPa}$, 1.6 MPa and 2.7 MPa.

The effect of the choice of adhesive properties on stress distribution at interface is shown in Fig. 11a. With the use of stiffer adhesive, the distribution of stresses are increasingly even, and that might be the reason for flexural cracks getting closely spaced in the experimental study of Macdonald and Calder [13]. Further investigation in Fig. 11b indicates that due to this effect, the flexural strains have dropped for stiffer adhesive, resulting in lesser number of flexural cracks. In Fig. 11b, after calibration and validation of FE model, a flexural crack appears on the surface of covercrete at a stain of 0.0001 and a complete crack at 0.003 . Therefore, values of strain lying within this range indicate progress of flexural cracks from crack initiation to complete failure. This property is further studies in Section 4.2.

The observations for the location of peak interfacial stresses are in agreement with the FE model of [3] and in disagreement with the theoretical model of Smith and Teng [4]. Teng et al. [3] and Ascione and Feo [5] found that peak stresses occur near plate end, and not at plate end as identified by Smith and Teng [4] and Roberts [7]. However, Teng et al. [3] noted zero stresses at plate ends; whereas, current FE model is in close agreement with the experimental observations of Charif [26]. For example, at the load of $60 \mathrm{kN}$, current FE model noted shear stress of $-0.38 \mathrm{MPa}$ at plate end which is in close agreement with that of $-0.36 \mathrm{MPa}$ noted by Charif [26].

\subsubsection{Specimen of Jones (Jones et al. [33])}

Behaviour of failure modes, in terms of crack initiation, debonding and crack propagation is captured through cohesive element degradation and validated against selective literature due to the extensive experimental work of Jones et al. [33] in this area. The beam is picked such that debonding cracks are noticed at all possible locations along the interface, that is, mid-span, shear-span (and plate-end). The numerical observations are gathered in Fig. 12.

The Fig. 12 indicates a complex case of interface debonding where the crack initiates at plate-end comparatively at lower load (at around $8.5 \mathrm{kN}$ ) to crack at mid-span (at load of around $26.3 \mathrm{kN}$ ), a first complete crack occurs at latter location mainly due to a steeper rate of propagation. The FE model captures crack initiation/ propagation more prominently as the steel starts to yield. With increasing load, the cracks are observed propagating outwards. Such behaviour is identical to a test-beam by Jones et al. [33]. At first failure, the numerical load capacity of $36 \mathrm{kN}$ is in close agreement with the corresponding experimental value $40 \mathrm{kN}$.

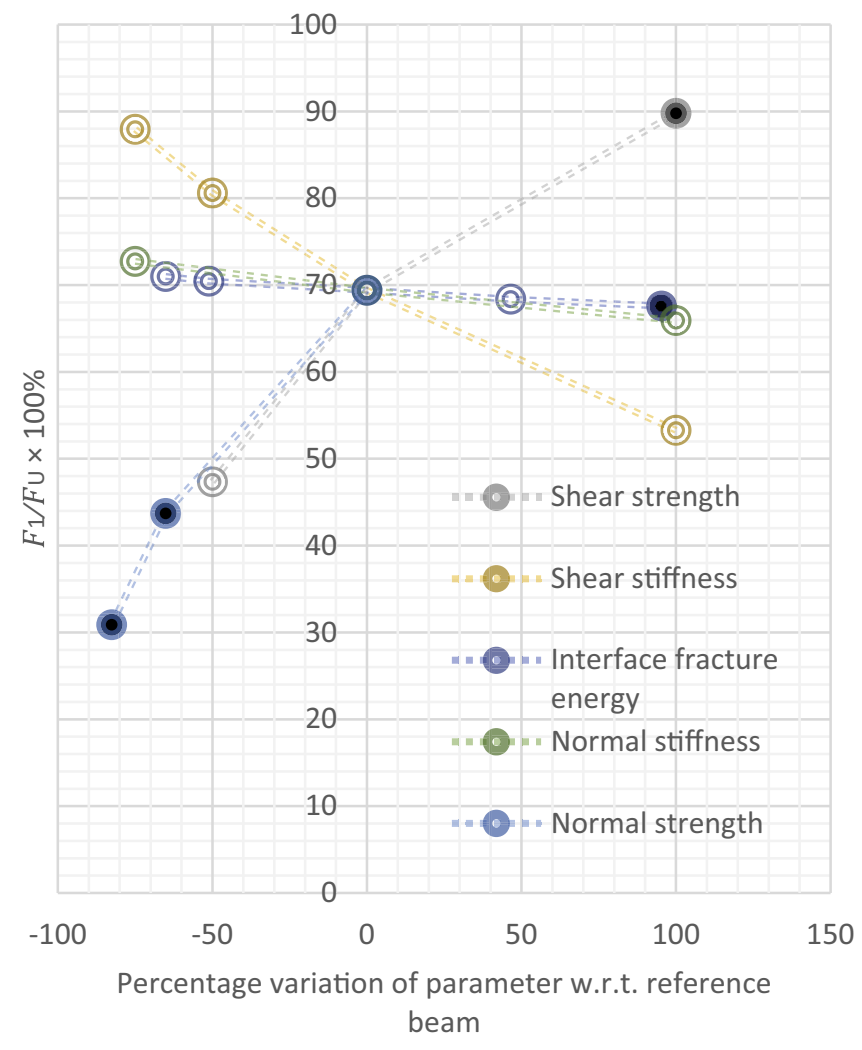

Fig. 13. Brittleness of debonding at plate-end for the choice of parameters.

\subsection{Effect of interface or adhesive properties}

The results are analysed and discussed based on the load of appearance of first crack and maximum ultimate capacity of the beam. The change in the mode of failure is noted from the appearance of first type of crack until ultimate capacity. Such an approach of analysis made it possible to realise how a changing parameter can affect the performance of a prematurely failing beam.

The effect of change in parameter is plotted against the brittleness of mode( $s$ ) of failure. The latter is checked by noting the achievable percentage of the ultimate carrying capacity of the beam at the appearance of first crack (particularly debonding types in this study). This is achieved by noting the load of appearance of crack (s) $F_{1}$ with respect to the ultimate capacity $F_{u}$ of a corresponding beam. Therefore, brittleness of failure can be defined as $F_{1} / F_{u} \times 100 \%$. Higher percentage may indicate the increase in the capacity of the beam at the appearance of first crack or a late crack formation; thereby, it also indicates that a relatively lower load is required after the appearance of first crack to achieve the ultimate capacity of beam. That is, higher percentage indicates an increase in brittleness of the $\operatorname{crack}(\mathrm{s})$ to lead to ultimate failure, which is undesirable compared to a less brittle failure. To identify relative control of parameters over a particular mode of failure, the parameters are studied within their practical ranges to effect brittleness of failure(s). It is because, a parameter causing high variations on brittleness of failure will have larger control over that particular mode of failure. Whereas, if the mode of failure is yielding of the plate (at mid-span), a higher percentage indicates increase in achievable capacity (in flexure).

In the following plots (see Fig. 13) to check brittleness of failure $(s)$, for example, the vertical axis represents the load at appearance of crack (debonding at plate-end) as the total percentage of ultimate load of the corresponding beam. The empty dots indicate the first mode of complete-failure as debonding types; while other failure types of peeling, yielding and diagonal cracks are dotted 
Table 1

Effect of parameters on brittleness of debondings at plate-end and mid-span and ultimate capacity.

\begin{tabular}{|c|c|c|c|c|c|}
\hline \multirow[t]{2}{*}{ Parameter } & \multirow[t]{2}{*}{ Range } & \multirow{2}{*}{$\begin{array}{l}\text { Percentage } \\
\text { change }\end{array}$} & \multicolumn{2}{|c|}{ Percentage ultimate load achieved w.r.t. load at first crack $\left(F_{1} / F_{u} \times 100 \%\right)$} & \multirow{2}{*}{$\begin{array}{l}\text { Ultimate maximum } \\
\text { capacity percentage variation }\end{array}$} \\
\hline & & & Debonding at plate-end & Debonding at plate-mid & \\
\hline \multirow[t]{3}{*}{$t_{s}^{\circ}(\mathrm{MPa})$} & 1 & -50 & 47.4 & 92.2 & -27.98 \\
\hline & 2 (reference) & 0 & 69.4 & 83.8 & 0 \\
\hline & 4 & 100 & 89.8 & (de-bonding at plate-end initiated at early stage) & 2.2 \\
\hline \multirow[t]{4}{*}{$K_{g \tau}(\mathrm{MPa} / \mathrm{mm})$} & 247.9 & -75 & 87.9 & 91 & -4.1 \\
\hline & 495.7 & -50 & 80.6 & 85.6 & 0 \\
\hline & $\begin{array}{l}991.4 \\
\text { (reference) }\end{array}$ & 0 & 69.4 & 83.8 & 0 \\
\hline & 1982.8 & 100 & 53.3 & (de-bonding at plate-end initiated at early stage) & 2.2 \\
\hline \multirow[t]{5}{*}{$G_{f_{\text {_interface }}}(\mathrm{MPa})$} & 0.015 & -65.1 & 70.99 & 85.7 & -2.2 \\
\hline & 0.021 & -51.2 & 70.5 & 85 & -1.5 \\
\hline & 0.043 (reference) & 0 & 69.4 & 83.8 & 0 \\
\hline & 0.063 & 46.5 & 68.4 & 82.6 & 1.5 \\
\hline & 0.084 & 95.4 & 67.6 & 81.6 & 2.7 \\
\hline \multirow[t]{3}{*}{$K_{g \sigma}(\mathrm{MPa} / \mathrm{mm})$} & 575 & -75 & 72.7 & 89 & -1.5 \\
\hline & 2300 (reference) & 0 & 69.4 & 83.8 & 0 \\
\hline & 4600 & 100 & 65.9 & 83 & 0.8 \\
\hline \multirow[t]{3}{*}{$t_{n}^{\circ}(\mathrm{MPa})$} & 0.5 & -82.6 & 30.9 & 86 & -8.2 \\
\hline & 1 & -65.2 & 43.7 & 87 & 0.8 \\
\hline & 2.87 & 0 & 69.4 & (de-bonding at plate-end initiated at early stage) & 0 \\
\hline
\end{tabular}

identically with black dot. The horizontal axis shows the percentage variation of parameters relative to reference values lying at origin.

An earlier warning of a failure can be signified by the appearance of first crack at lower load of the total ultimate capacity; therefore, the relative variations in the maximum ultimate capacities of the beams are also recorded (Table 1). The Ultimate Load $F_{u}$ for reference beam is obtained as $134 \mathrm{kN}$.

\subsubsection{Shear and tensile stiffness of adhesive at interface}

For the given range of shear and normal stiffness, the first mode of complete failure remained unaffected at debonding at plate end. Table 1 indicates that the load of appearance of debonding crack at plate end decreased significantly with the increase in stiffness of adhesive in either directions (transverse or normal). The interfacial crack appeared at $53 \%$ of ultimate capacity for the corresponding beam with $100 \%$ increase in shear stiffness. Such percentage is found to increase to $88 \%$ and $81 \%$ from $69 \%$ (reference beam) if the shear stiffness is reduced by $75 \%$ and $50 \%$ respectively.
It is also noted that the ultimate capacities are affected only slightly; the ultimate capacity decreased by $1.5 \%$ for the $75 \%$ reduction in normal stiffness, while the ultimate capacity was increased by only $0.8 \%$ if the normal stiffness is increased by $100 \%$. Such behaviour indicates a relatively early appearance of premature cracks with the increase in stiffness. It can be seen that if the normal stiffness of interface was increased by $100 \%$, the interfacial crack at plate end appeared at around $66 \%$ of ultimate capacity of the corresponding beam; while this load was $73 \%$ for reduced normal stiffness of $75 \%$ of the reference value.

\subsubsection{Shear and tensile strength at interface}

The load of appearance of debonding crack at plate end increased significantly with the increase in strength. For $50 \%$ of strength, a relatively early appearance and formation of debonding dominated over other premature failures of the beam.

With $50 \%$ reduction in strength, reduction in the maximum ultimate capacity is $28 \%$; while $100 \%$ increase in strength resulted only small increase in the capacity by around $2 \%$. This indicates that an

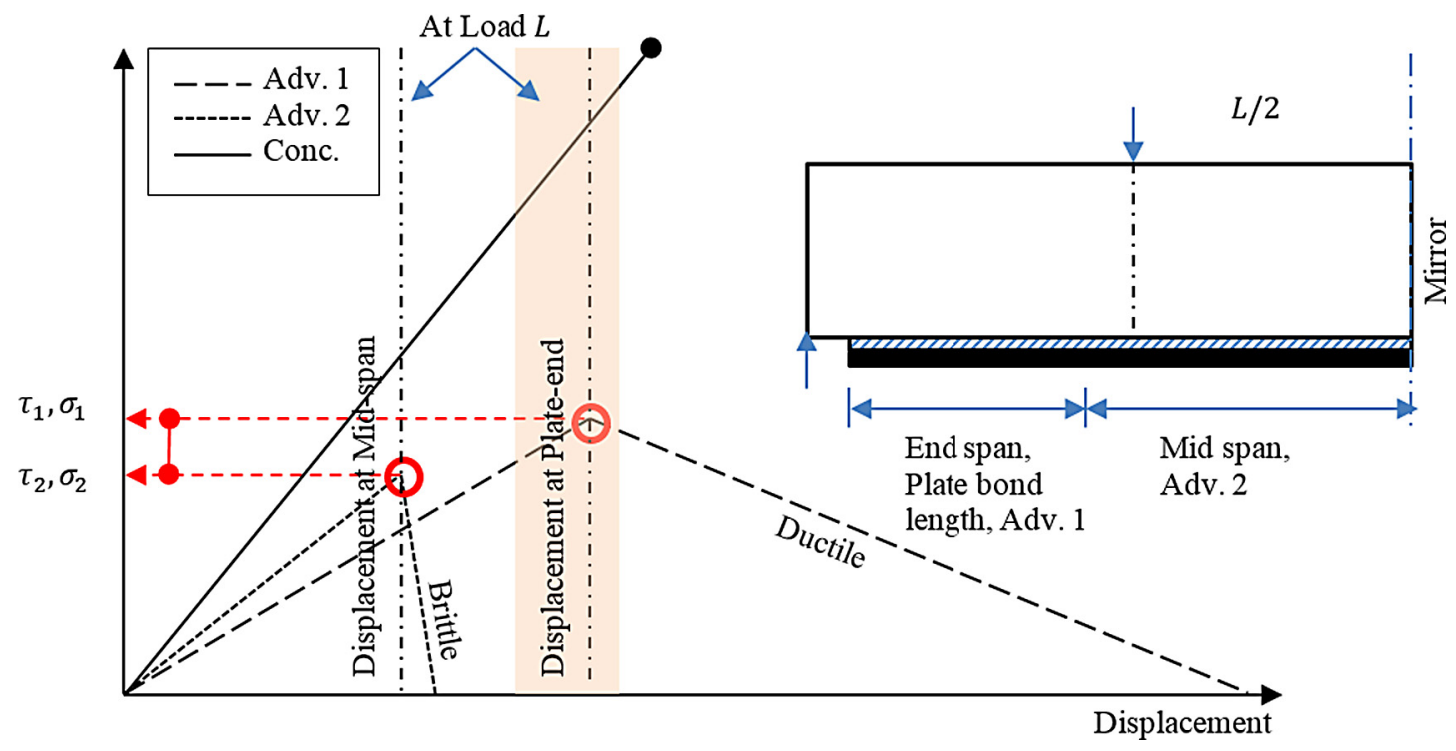

Fig. 14. Choice of adhesive properties at interface as a failure mitigation technique. 
almost maximum limit for ultimate capacity is reached that can be obtained by increasing interfacial strength in transverse direction.

For reduced normal strength, the first mode of complete failure changed from debonding at plate end to different mode of failure (that is peeling; which is out of the scope of this article). The ultimate capacity remained largely unaffected for normal strength equivalent to 0.5 times shear strength, while it was significantly reduced by $8.2 \%$ for $t_{n}^{\circ}$ (equivalent to $25 \% t_{s}^{\circ}$ ).

\subsubsection{Crack energy at interface}

Debonding and other types of cracks are equally affected. If the crack energy at the interface are kept around $-65 \%,-50 \%, 50 \%$ and $100 \%$ of the reference value, the interfacial crack (as the first crack) at plate end appeared at around $71 \%, 70.5 \%, 68 \%$ and $67.6 \%$ of the ultimate capacity.

\section{Conclusion}

A strategic approach is made, which is capable of idealising the behaviour at interface in the form of traction-separation model (through Cohesive-Zone-Model) to represent interface cracks in retrofitted RC beam, meanwhile this model is used to investigate the effect of the properties of adhesive. In addition, such an approach is ideal for the practical problem that does not account for the tensile strength of element (adhesive) in the transverse direction or compressive strength in normal direction. However, it suits the behaviour and purpose of adhesive as a component for structure integrity and not for structural strengthening.

The adoption of CZM in the form of proposed model, where the initial stiffness is now identified as material property of adhesive, has made it possible to use CZM for dual purposes, which are to define adhesive as well as crack formations. It is now possible that the location of formation and the behaviour of interfacial crack can be simply controlled through the choice of adhesive type. Under stress, it is now known that the debonding crack forms and thus propagates within the weakest component of critical region. Under mixed mode stresses, it is possible to consider the propagation of flexural cracks to cause interfacial debonding such as to depict the experimental observations of Oehlers [9].

To deal with the observation that the failure capacities of the beams may not be dependent on the mode of failure, a new term is coined as brittleness of failure such that, the lower values of brittleness of failure are desirable to identify failure warning on the structure and locate critical regions of concern to serviceability engineer that need extra attention before a beam can fail. The study yields to the following new findings.

The increase in shear stiffness at interface reduced the overall brittleness of the failing section. This is noticed through the appearance of interfacial crack at relatively lower percentage of their corresponding ultimate capacities. It is noted that for reduced shear stiffness the appearance of first crack changed from interfacial crack to different crack type.

Certainly, a warning crack appears prior to beam failing prematurely at ultimate capacity with the increase in stiffness. Increase in the normal stiffness of adhesive reduced the brittleness of the crack. Meanwhile, the load of appearance of flexural crack at plate end remained unaffected. The appearance of first crack remained to be interfacial crack at plate end. Clearly, the normal-stiffness of the interface is showing significant influence on the formation of debonding crack types.

It is observed that the brittleness of the prematurely failing beam increased with the increase in the transverse strength of the interface. If the transverse strength is reduced by $50 \%$, the debonding crack at plate end appeared at around half the loading capacity (47\%) for the corresponding beam. With the increase in transverse strength by $100 \%$, the debonding crack at plate end appeared at around $90 \%$ the loading capacity of the corresponding beam. Such behaviour indicates a relatively early appearance of premature cracks with reduced transverse strength.

A decrease in normal strength at interface reduced the brittleness of the beam. The appearance of first crack remained interfacial crack at plate end. Table 1 indicates that the load of appearance of debonding at plate end decreased significantly with the reduction in normal strength of adhesive. It can be seen from Fig. 13 that if the normal strength of interface is taken at $50 \%$ and $25 \%$ of shear strength (of $2.87 \mathrm{MPa}$ at reference value), the debonding crack at plate end appeared at $43.7 \%$ and $31 \%$ of the ultimate capacity of corresponding beams as compared to $69.4 \%$ for reference beam.

As seen from the appearance of first crack (here interfacial crack at plate end), increase in crack energy significantly reduces the brittleness of crack (Fig. 13), but not the appearance of crack. The first mode of complete failure remained unaffected with debonding at plate end, although until other type of failure is seen for relatively higher value of fracture energy of $0.084 \mathrm{~N} / \mathrm{mm}$.

\subsection{Recommendations}

Following the observations made from parametric study, authors have suggested a design approach and recommendations on the choice of material properties of the adhesive as a preferable material (to take damage) over concrete. It is proposed that the choice of adhesive can act as a mitigating technique or to regenerate a failure warning particularly at two different (critical) locations of the beam, that are plate end and mid span (see Fig. 14). Meanwhile, the design recommendations should be maintained such that the length of adhesive type at plate end may not be less than the effective bond length of the plate [17,34,35].

Fig. 14 shows that an external plate can be adhered to concrete surface with adherent composing of different adhesive types (as Adv. 1 and Adv. 2) along the length of the plate. It is assumed that the adhesive at mid-span (Adv. 2) is stiffer and weaker than the adhesive at plate-end (Adv. 1); while the strength of concrete is higher than the adhesives. There are no restrictions on the relative modulus between concrete and adhesives; however, a relatively high modulus is indicated for concrete so as to represent test literature.

The adoption of stiff adhesive at mid-span will assist in uniform redistribution of flexural cracks; and the soft adhesive at plate-end (s) will delay initiation of debonding and generate lower stresses within the adjacent concrete.

At a load $L$, it is noteworthy that due to relatively larger interfacial stresses at plate end, the strains or displacements generated will be larger than those generated at mid-span. Therefore, if it is to assume same adhesive (Adv. 1 only) embedded throughout, it is possible that a crack has already initiated at plate-end (due to higher stresses) at the time of crack initiation at mid-span. To represent this, displacement range of a shaded area indicates possible differences of displacement magnitudes at plate-end and midspan. Therefore, to accommodate this, adoption of a relatively weaker as well as brittle adhesive (Adv. 2) at mid-span will undergo cracking at a lower stress. Therefore, while the adhesive at plate-end (Adv. 1) is still intact, the cracking adhesive (noticed at complete crack) at mid-span will observe failure warning. In addition, a relatively ductile adhesive (Adv. 1) will resist a complete disintegration of the plate from concrete (at plate-ends).

\section{Acknowledgement}

The present work is part of corresponding author's $\mathrm{PhD}$ thesis, funded ${ }^{1}$ by the School of Civil and Building Engineering and submit-

\footnotetext{
${ }^{1}$ Financial support - Research Studentship, Loughborough University, UK
} 
ted under the supervision of Dr. Jamal El-Rimawi and, Prof. Vadim V. Silberschmidt at Loughborough University (UK). The author would also like to express his gratitude towards his supervisors for providing excess to required facilities and research group (Mechanics of Advanced Materials) at the School of Mechanical and Manufacturing Engineering, Loughborough University (UK).

\section{References}

[1] Sebastian W. Significance of midspan debonding failure in FRP-plated concrete beams. J Struct Eng 2001:127(7):792-8.

[2] Alfano G, Rosati L, Simonelli G. Modelling of failure mechanisms in RC beams retrofitted with FRP in flexure. In: Onate E, Owen DRJ, editors. VIII International conference on computational plasticity. Barcelona: CIMNE; 2005. p. 1-4.

[3] Teng JG, Zhang JW, Smith ST. Interfacial stresses in reinforced concrete beams bonded with a soffit plate: a finite element study. Constr Build Mater 2002;16 (1):1-14.

[4] Smith ST, Teng JG. Interfacial stresses in plated beams. Eng Struct 2001;23 (7):857-71.

[5] Ascione L, Feo L. Modeling of composite/concrete interface of RC beams strengthened with composite laminates. Composites Part B 2000;31(67):535-40.

[6] Jones R, Swamy RN, Charif A. Plate separation and anchorage of reinforced concrete beams strengthened by epoxy-bonded steel plate. Struct Eng 1988;66 (5):85-94.

[7] Roberts TM. Approximate analysis of shear and normal stress concentrations in the adhesive layer of plated RC beams. Struct Eng 1989;67(12):229-33.

[8] Roberts TM, Haji-Kazemi H. Theoretical study of the behaviour of reinforced concrete beams strengthened by externally bonded steel plates. Proc Inst Civ Eng 1989;87(Part 2):39-55.

[9] Oehlers DJ. Development of design rules for retrofitting by adhesive bonding or bolting either FRP or steel plates to RC beams or slabs in bridges and buildings. Composites Part A 2001;32(9):1345-55.

[10] De Lorenzis L, Zavarise G. Cohesive zone modeling of interfacial stresses in plated beams. Int J Solids Struct 2009;46(24):4181-91.

[11] Hussain $M$ et al. Flexural behavior of precracked reinforced concrete beams strengthened externally by steel plates. ACI Struct J 1995;92(1):14-22.

[12] Swamy RN, Mukhopadhyaya P, Lynsdale CJ. Strengthening for shear of RC beams by external plate bonding. Struct Eng 1999;77(12):19-30.

[13] Macdonald MD, Calder AJJ. Bonded steel plating for strengthening concrete structures. Int J Adhes Adhes 1982;2(2):119-27.

[14] Macdonald MD. Strength of bonded shear joints subjected to movement during cure. Int J Cem Compos Lightweight Concrete 1981;3(4):267-72.

[15] Reeve BZ. Effect of adhesive stiffness and CFRP geometry on the behaviour of externally bonded CFRP retrofit measures subject to monotonic loads. United Kingdom: Civil Engineering, University of Pittsburgh; 2005.
[16] Oh B, Cho J, Park D. Failure behavior and separation criterion for strengthened concrete members with steel plates. J Struct Eng 2003;129(9):1191-8.

[17] Heathcote PM. Theoretical and experimental study on FRP or steel plated R.C. beams. Loughborough, Leicestershire, United Kingdom: Civil and Building Engineering, Loughborough University; 2004.

[18] Rots J. Smeared and discrete representations of localized fracture. Int J Fract 1991;51(1):45-59.

[19] Camanho PP, Davila CG, de Moura MF. Numerical simulation of mixed-mode progressive delamination in composite materials. J Compos Mater 2003;37 (16):1415-38.

[20] Meo M, Thieulot E. Delamination modelling in a double cantilever beam. Compos Struct 2005;71(3-4):429-34.

[21] Allix O, Ladevéze P, Corigliano A. Damage analysis of interlaminar fracture specimens. Compos Struct 1995;31(1):61-74.

[22] Li S et al. Use of mode-I cohesive-zone models to describe the fracture of an adhesively-bonded polymer-matrix composite. Compos Sci Technol 2005;65 (2):281-93.

[23] Abaqus I, Abaqus CAE. Abaqus/CAE user's manual. Providence, RI, USA: Dassault Systèmes; 2011.

[24] Corrado M, Paggi M. Nonlinear fracture dynamics of laminates with finite thickness adhesives. Mech Mater 2015;80(Part B):183-92.

[25] Khan MA. FE investigation of failure modes at the soffit of a steel plated RC beam. Loughborough, Leicestershire, United Kingdom: School of Civil and Building Engineering, Loughborough University; 2014.

[26] Charif A. Structural behaviour of reinforced concrete beams strengthened by epoxy bonded steel plates. Sheffield, United Kingdom: Civil and Structural Engineering, Faculty of Engineering, The University of Sheffield; 1983.

[27] Sikadur. Technical product data sheet [cited 2012 July 7]; Available from http://www.sikaconstruction.com/; 2012.

[28] BSI. Structural use of concrete. London: British Standards Institution; 1985.

[29] 318, A.. Building code requirements for reinforced concrete. American Concrete Institute; 2002.

[30] Mailvaganam NP. Effective use of bonding agents. National Research Council of Canada, Construction Technology Update; 1998. p. 11.

[31] Wittmann FH. Crack formation and fracture energy of normal and high strength concrete. Sadhana 2002;27(4):413-23.

[32] Griffiths R, Holloway DG. The fracture energy of some epoxy resin materials. J Mater Sci 1970;5:302-7.

[33] Jones R, Swamy RN, Ang TH. Under- and over-reinforced concrete beams with glued steel plates. Int J Cem Compos Lightweight Concrete 1982;4(1):19-32.

[34] Horiguchi T, Saeki N. Effect of test methods and quality of concrete on bond strength of CFRP sheet. In: Proc., FRPRCS-3: 3rd international symposium on non-metallic (FRP) reinforcement for concrete structures, Sapporo, Japan; 1997.

[35] Wu Z, Yuan H, Niu H. Stress transfer and fracture propagation in different kinds of adhesive joints. J Eng Mech 2002;128(5):562-73. 